\title{
LETTER TO THE EDITOR \\ A 24-hour Telephone Support Service: Can it really replace a relationship built over time?
}

*Tara Kielmann ${ }^{\text {, }}$

Alison Powella, Guro Hubyb, Hilary Pinnock ${ }^{a}$

a Centre for Population Health Sciences

- General Practice, University of

Edinburgh

b Centre for Integrated Healthcare

Research, University of Edinburgh

*Correspondence:

Mrs Tara Kielmann,

Centre for Population Health Sciences -

General Practice,

The University of Edinburgh,

Doorway 3, The Old Medical School,

Teviot Place,

Edinburgh,

EH8 9DX,

United Kingdom

Tel: +44(0)1316518102

Fax: +44 (0)131650 9119

E-mail: tkielmann@hotmail.com

17th October 2010

C 2010 Primary Care Respiratory Society UK. All rights reserved

\section{Dear Sir,}

We read with interest Hurst et al's paper, which showed that the use of a telephone support service for patients with high-risk COPD was associated with a reduction in hospital admissions. ${ }^{1}$

These findings resonate with our qualitative study in which patients with long-term respiratory illnesses expressed a need for flexible access to professional advice (face-toface, by telephone or e-mail) to feel secure in the self-management of their illness. ${ }^{2}$ However, in line with previous research, ${ }^{3,4}$ the majority of the patients we interviewed also highlighted the importance of a trusted relationship with their health professional within which they could not only seek advice and support but could also discuss issues they deemed important in the management of their disease and "be taken seriously". ${ }^{2}$

This suggests that a key factor in the success of the 24-hour telephone service was that patients could speak to a specialist whom they knew and trusted. The authors, however, indicate that the key component leading to the success of the service was "the detailed patient-specific information available to the healthcare professional manning the telephone, thus enabling appropriate advice to be given". We would question whether the availability of detailed, in-depth patient background data is really enough to create the same levels of trust between patient and professional as a relationship built over time.

The Consultation on a National Strategy for COPD highlights the need for 'access to 24-hour advice for people with COPD' and practical implementation is being investigated. 5 The relatively low call volume suggests that to be cost-effective, a service would need to span more than a single Primary Care Trust, thus losing the personal touch. The outcomes and user satisfaction reported by Hurst et al. are encouraging, but it cannot be assumed that a service manned by an unknown health professional would be equally effective even if extensive health records were available.

\section{Conflict of interest declaration}

None to declare.

\section{References}

1. Hurst JR. Fitzgerald-Khan F. Quint JK, et al. Use and utility of a 24-hour Telephone Support Service for 'high risk' patients with COPD. Prim Care Resp J 2010;19(3):260-5. http://dx.doi.org/10.4104/pcrj.2010.00035

2. Kielmann T, Huby G, Powell A, et al. From support to boundary: a qualitative study of the border between self care and professional care. Pat Ed Counse/ 2010;79:55-61. http://dx.doi.org/10.1016/j.pec.2009.07.015

3. Thompson $\mathrm{AGH}$. The meaning of patient involvement and participation in health care consultations: a taxonomy. Soc Sci Med 2007;64:1297-310. http://dx.doi.org/10.1016/j.socscimed.2006.11.002

4. Charles C, Gafni A, Whelan T. Decision-making in the physician-patient encounter. Soc Sci Med 1999;49:651-61. http://dx.doi.org/10.1016/S0277-9536(99)00145-8

5. Department of Health. Consultation on a Strategy for Services for Chronic Obstructive Pulmonary Disease (COPD) in England. London: DoH, 2010

Available online at http://www.thepcrj.org 